\title{
ИССЛЕДОВАНИЕ ЭФФЕКТИВНОСТИ РЕАЛИЗАЦИИ ПСИХОЛОГО-ПЕДАГОГИЧЕСКОЙ ПРОГРАММЫ ФОРМИРОВАНИЯ ГРАЖДАНСКОЙ ИДЕНТИЧНОСТИ У ОБУЧАЮЩИХСЯ СТАРШЕГО ПОДРОСТКОВОГО ВОЗРАСТА
}

\section{A STUDY OF THE EFFECTIVENESS \\ OF IMPLEMENTATION OF PSYCHO- \\ PEDAGOGICAL PROGRAM OF FORMATION OF CIVIL IDENTITY AMONG STUDENTS OLDER ADOLESCENTS}

\section{A. Galchenko}

Summary: The article presents the results of determining the effectiveness of experimental work on the formation of civil identity in students of older adolescence. As psychological determinants of the formation of civil identity, the following were identified: the ability to conceptualize in the field of civil issues, the valence of civic identity, reflexivity, the nature of the structural organization of motivation for civil activity. As a result of the implementation of the program, changes in the indicators of the selected determinants and, as a result, positive changes in the status profiles of civil identity of adolescents were established.

Keywords: civil identity, determinants of identity, ability to conceptualize, valence of civil identity, civil activity.

\section{Введение}

$\mathrm{O}$ дной из ключевых характеристик современного российского общества является его транзитивность - множественность и динамичность изменений при сохранении значительного числа прежних ценностей, форм и моделей отношений (А.Д. Андреева). Такая амбивалентность социальной среды, выражающаяся одновременно в традиционализме и модернизации, а также высокий уровень неопределенности и вариативности социальной среды затрудняют создание единого общегосударственного ценностно-идентификационного конструкта, который может быть заложен в основу гражданской общности. В свою очередь, именно зрелость гражданского самосознания является обязательным условием становления стабильного, полноценно функционирующего общества.

Педагогическому сообществу отводится особая роль по созданию образовательной среды, способствующей становлению осознанной гражданской идентичности молодого поколения. Вместе с тем анализ педагогических практик по проблемам формирования граждан-
Гальченко Анна Сергеевна

Ученый секретарь, ГБОУ ДПО РК «Крымский республиканский институт постдипломного педагогического образования» (2. Симферополь)

asg.7@mail.ru

Аннотация: В статье представлены результаты определения эффективности опытно-экспериментальной работы по формированию гражданской идентичности у обучающихся старшего подросткового возраста. В качестве психологических детерминант формирования гражданкой идентичности были определены: способность к концептуализации в области гражданской проблематики, валентность гражданской идентичности, рефлексивность, характер структурной организации мотивации гражданской активности. По итогам реализации программы установлены изменения в показателях выделенных детерминант и как результат - положительные изменения в статусных профилях гражданской идентичности подростков.

Ключевые слова: гражданская идентичность, детерминанты идентичности, способность к концептуализации, валентность гражданской идентичности, гражданская активность. ской идентичности молодежи свидетельствует о том, что научный потенциал психологического знания используется не в достаточной степени.

\section{Обзор послеАних исслеАований}

Теоретические основания феномена гражданской идентичности в отечественной психологии разрабатывались в научных трудах А.Г. Асмолова, Н.В. Безгиной, Н.Л. Ивановой, Г.Б. Мазиловой и др. $[1,2,8]$. Научный вклад в понимание закономерностей взаимосвязи гражданской и этнической идентичности внесли исследования М.В. Дробовцевой, М.В. Котовой, К.В. Злоказова, Н.И. Леонова, А.А. Фомина и др. [4, 7]. Ряд исследований Т.В. Евгеньевой, В.В. Регнацкого, О.И. Ефремовой направлен на изучение оснований для самоидентификации, а также представлений, которые отражают систему убеждений и ценностей, относящихся к гражданской (национальной) идентичности $[5,6]$.

Целый ряд исследований Э. Финелл, К. Либкинда, М. Кеммельмейера и Д. Винтера посвящен выявлению и объяснению факторов, влияющих на национальную 
идентичность [11, 12]. В трудах Й. Мейеса, Б. Дюрье, Н. Ванбеселаере и Ф. Бойена изучаются взаимосвязи между внутригрупповой идентификацией и национальными предрассудками [13].

Обширный круг исследований по гражданской идентичности в современной отечественной психологии преимущественно сосредоточен в области социальной, дифференциальной психологии, психологии личности. В значительно меньшей степени проблематика исследований носит практический характер в области педагогической психологии.

Продолжая научный поиск в данном направлении, автор статьи исследует уровень и характер гражданской идентичности через статусную концепцию эго-идентичности Дж. Марсиа, теоретически обоснованы и эмпирически исследованы психологические детерминанты формирования статусов гражданской идентичности [10]. В качестве психологических детерминант были определены: способность к концептуализации в области гражданской проблематики, валентность гражданской идентичности и уровень рефлексивности личности, характер структурной организации мотивации гражданской активности. На основании полученных результатов исследований разработана и апробирована психолого-педагогическая программа, направленная на формирование осознанной гражданской идентичности учащихся старшего подросткового возраста.

В программе предусмотрена реализация трех основных планов работы.

Первый план работы - это формирование зрелых концептуальных структур, релевантных базовым идентификационным понятиям гражданской идентичности: «гражданское общество», «гражданин», «гражданские ценности» (свобода, ответственность, патриотизм и др.), «гражданская позиция», «гражданский долг». Под Концептуальной структурой понимается ментальная структура «внутри» индивидуального ментального опыта, выступающая в качестве психического носителя понятия (как историко-культурного элемента системы знаний) [9].

Второй план работы - развитие критического мышления. Технологической основой формирования критического мышления была выбрана модель трех стадий: «вызов - реализация смысла (осмысление) - рефлексия (размышление)». Данная модель разработана Дженни Д. Стилл, Кертис С. Мередит, Чарлз Темпл и Скотт Уолтер в рамках технологии развития критического мышления через чтение и письмо [14].

К задачам третьего плана работы относится формирование у подростков осознания того, как интерпретация социально-политических событий влияет на возникновение определенных гражданских чувств, отношений и гражданскую активность. Понимание подростками того, что мысли являются интерпретацией фактов и могут быть как верными, так и неверными позволяет перейти к работе по выделению и категоризации мыслительных искажений («Чтение мыслей», «Предсказание будущего», «Использование ярлыков», «Обесценивание», «Негативный фильтр» и т. д.), оценке их фактологической обоснованности и логичности, а также проверке с точки зрения реалистичного, сбалансированного и разностороннего отображения социальной реальности.

Методическое обеспечение трех основных направлений работы было создано на основе модифицированного варианта комплекта заданий М.А. Холодной, разработанного для изучения особенностей состава и строения ментальных структур как носителей свойств понятийного мышления [9], заданий, которые составлены с учетом психолого-дидактических принципов формирования научных понятий, изложенных в трудах А.Г. Буткина, И.А. Володарской, Н.Ф. Талызиной [3], техник формирования критического мышления и отдельных техник когнитивно-поведенческой терапии.

\section{Материалы и методы}

Цель - определение эффективности опытно-экспериментальной работы с системой психологических детерминант формирования гражданской идентичности у обучающихся старшего подросткового возраста.

Эмпирическую базу исследования составили 50 обучающихся средних общеобразовательных школ и колледжа г. Симферополя. Из них контрольная и экспериментальная выборки включали по 25 человек, которые находились в статусе моратория в отношении гражданской идентичности.

Для определения статуса гражданской идентичности подростков разработана авторская анкета. Анкета предусматривает четыре шкалы, выделенные в соответствии с четырьмя статусами гражданской идентичности: диффузный, предопределенный, мораторий и достигнутый статус. Каждая шкала включает по шесть утверждений в отношении различных аспектов гражданской жизнедеятельности. Распределение баллов между статусами представляет индивидуальный (групповой) статусный профиль гражданской идентичности. Статус определяется по доминирующему баллу.

Способность к концептуализации в области гражданской проблематики определялась методом контент-анализа текстов, зафиксированных в процессе структурированной беседы со старшеклассниками. На основании положений теории понятийного мышления М.А. Хо- 
лодной [9] выделены критерии анализа текстов: формальный ответ, фактологического типа; высказывания аргументирующего типа; высказывания систематизирующего типа; интерпретации, в том числе варьирующие и альтернативные; выявление респондентом имплицитных признаков перечисленных фактов; выявление причинно-следственных связей.

Диагностика мотивации гражданской активности подростков осуществлялась при помощи методики выявления мотивационной структуры общественно полезной деятельности подростка, разработанной О.В. Лишиным на базе теста LMT B. Хеннига.

Валентность гражданской идентичности измерялась при помощи методики «Типы гражданской идентичности» М.В. Борисова, рефлексивность - методики определения уровня рефлексивности А.В. Карпова, В.В. Пономаревой.

Методы математической статистики: критерий Вилкоксона, коэффициент ранговой корреляции Спирмена.

\section{Результаты исследования}

С целью определения статистической значимости сдвига в показателях выраженности способности к концептуализации до и после реализации программы в экспериментальной выборке и в показателях двух замеров в контрольной выборке был применен критерий Вилкоксона. Установлены статистически значимые изменения в увеличении показателей способности к концептуализации в области гражданской проблематики в экспериментальной выборке $(p=0,002)$ и отсутствие значимых сдвигов в контрольной выборке $(p=0,63)$.

В результате проведения психолого-педагогической работы у подростков повышается способность оперировать имеющимися данными (событиями, фактами) в области гражданской проблематики, устанавливать причинно-следственные связи, выявлять зависимости, которые скрыты за поверхностью наглядного опыта и отражают обобщенные закономерности. В рассуждениях о явлениях социальной действительности присутствуют характеристики системности (упорядоченность, структурность, иерархичность и т.п.). Понятия (явления), на предмет которых рассуждает субъект, локализованы в определенной системе отношений.

С целью определения значимости сдвига в количественной выраженности шкал валентности гражданской идентичности в личностных профилях подростков экспериментальной и контрольной выборок по результатам двух измерений применялся критерий Вилкоксона (таблица 1).

По итогам реализации программы установлено, что в личностных профилях подростков из экспериментальной выборки снизились показатели шкал гиперпозитивного и негативного отношения к гражданской принадлежности и увеличились показатели по шкале «позитивная валентность гражданской идентичности». В контрольной выборке подростков при первом измерении и повторном измерении по истечению времени равного периоду проведения программы значимых сдвигов обнаружено не было.

Сравнение показателей рефлексивности подростков из экспериментальной выборки до и после реализации психолого-педагогической работы (значимость сдвига проверялась при помощи критерия Вилкоксона) позволяет сделать вывод об увеличении способности к рефлексии по итогам прохождения программы (среднее арифметическое до прохождения программы - 127,96, после - 132,76; $\left.p<0,001^{* * *}\right)$. При отсутствии подобного психолого-педагогического сопровождения значимых количественных сдвигов в изменении рефлексивности не обнаружено (среднее арифметическое при первом замере в контрольной выборке - 128,08, при втором $127,72 ; p=0,58)$.

Посредством подсчета коэффициентов ранговой

Статистическая значимость изменения данных по валентности гражданской идентичности в экспериментальной и контрольной выборках по результатам двух измерений

\begin{tabular}{|c|c|c|c|c|c|c|}
\hline \multirow[b]{2}{*}{$\begin{array}{l}\text { Серии Шкалы замеров } \\
\text { валентности }\end{array}$} & \multicolumn{3}{|c|}{ Экспериментальная выборка } & \multicolumn{3}{|c|}{ Контрольная выборка } \\
\hline & До программы & После программы & \multirow[t]{2}{*}{ T-Kритерий (p) } & 1-е измерение & 2-е измерение & \multirow[t]{2}{*}{$T$-Критерий (p) } \\
\hline & \multicolumn{2}{|c|}{ средние арифметические } & & \multicolumn{2}{|c|}{ средние арифметические } & \\
\hline гиперпозитивная & 5,24 & 4,52 & $0,007^{* *}$ & 5,32 & 5,28 & $p=0,84$ \\
\hline позитивная & 11,16 & 13,28 & $\mathrm{p}<0,001^{* * *}$ & 11,28 & 11,36 & $p=0,68$ \\
\hline негативная & 11,36 & 9,92 & $p<0,001^{* * *}$ & 11,80 & 11,88 & $p=0,73$ \\
\hline
\end{tabular}

** Различие является статистически значимым на уровне значимости $\mathrm{p}<0,01$.

*** Различие является статистически значимым на уровне значимости $p<0,001$. 
корреляции Спирмена была проведена процедура расчета корреляций между мотивами гражданской активности в экспериментальной и контрольной выборках и принято решение оценивать изменения по результатам проведения программы только в устойчивых связях, которые обнаружены во всех исследуемых выборках (экспериментальной - 25 чел. и контрольной - 25 чел).

В качестве устойчивых корреляционных связей мотивов гражданской активности подростков в статусе моратория, т.е. в состоянии кризиса и активного поиска собственной позиции в отношении гражданской принадлежности были определены корреляции между:

- мотивом эмоционального восприятия процесса действования - М1 и мотивом самоутверждения M3 (экспериментальная выборка - 0,473944*, контрольная - 0,69668**);

- мотивом эмоционального восприятия процесса действования - М1 и мотивом принципиальной ответственности и добросовестности - М9 (экспериментальная выборка - 0,489445*, контрольная $-0,63016^{* * *}$;

- мотивом самоутверждения - M3 и мотивом принципиальной ответственности и добросовестности - М9 (экспериментальная выборка $0,736513^{* * *}$, контрольная $\left.-0,68153^{* * *}\right)$.

Связь мотива 1 с мотивом 3 может свидетельствовать о том, что положительное отношение к проявлению гражданской активности является таковым в результате возможности самоутверждения. Связь мотива 9 с мотивом 3, гипотетически связана с решением задачи укрепления самооценки (ответственность и добросовестность - высокий результат - самоутверждение). Корреляция общественных мотивов с мотивом положительного отношения к гражданской активности (M1, М9) свидетельствует о положительной динамике формирования гражданского самосознания подростков. Вместе с тем опосредованность общественного мотива (М9) гражданской активности мотивами других типов затрудняет их функционирование в качестве самостоятельных компонентов мотивационной сферы.

По результатам реализации программы повторно была проведена диагностика мотивации гражданской активности старшеклассников и установлены корреляционное связи между мотивами (таблица 2).

Мотивационная структура гражданской активности учащихся в эмпирической выборке сохранила ранее установленные связи. Изменения отмечены в уровне значимости корреляционной связи между мотивом 3 и мотивом 9 (до реализации программы уровень значимости корреляции установлен при $\mathrm{p}<0,001$, после $-\mathrm{p}<0,05)$. Корреляция между указанными мотивами стала слабее, т.е. при выполнении той или иной социально полезной деятельности мотивация ответственности и добросовестности уже у меньшего количества старшеклассников и в меньшей степени связана с желанием самоутверждения, укрепления самооценки, соответственно в меньшей степени направлена на самого себя. Увеличилась значимость корреляционной связи между мотивом эмоционального восприятия процесса действования и мотивом принципиальной ответственности и добросовестности.

Сравнение количественных показателей шкал М3, M8, M9 до и после реализации программы свидетельствует о том, что мотив самоутверждения (М3) значимо не изменился (критерий Т Вилкоксона - $p=0,063$ ), показатели же мотивов ориентации на пользу незнакомым людям (М8), а также принципиальной ответственности и добросовестности (М9) при выполнении социально значимой деятельности увеличились (критерий Т Вилкоксона $\left.-p=0,003^{* *} ; p=0,021^{*}\right)$. В контрольной выборке подобных изменений не обнаружено (шкала М3: Т - p=0,21; шкала M8: T - $p=0,25$; шкала M9: $\mathrm{T}-\mathrm{p}=0,25)$.

Корреляционные связи мотивов гражданской активности в экспериментальной выборке до и после реализации программы и в контрольной выборке в первом и втором измерении

\begin{tabular}{|c|c|c|c|c|}
\hline \multirow{2}{*}{ Мотив } & \multicolumn{2}{|c|}{ Экспериментальная выборка n-25 } & \multicolumn{2}{|c|}{ Контрольная выборка n-25 } \\
\cline { 2 - 5 } & $\begin{array}{c}\text { измерение до реализации } \\
\text { программы }\end{array}$ & $\begin{array}{c}\text { измерение после реализа- } \\
\text { ции программы }\end{array}$ & $\begin{array}{c}\text { первичное измерение } \\
\text { измерение по истечении } \\
\text { времени }\end{array}$ \\
\hline M1,3 & $0,473944^{*}$ & $0,401127^{*}$ & $0,69668^{* * *}$ & $0,70935^{* * *}$ \\
\hline M1,9 & $0,489445^{*}$ & $0,568285^{* *}$ & $0,63016^{* * *}$ & $0,607065^{* *}$ \\
\hline M3,9 & $0,736513^{* * *}$ & $0,436568^{*}$ & $0,68153^{* * *}$ & $0,632714^{* * *}$ \\
\hline
\end{tabular}

* Различие является статистически значимым на уровне значимости $\mathrm{p}<0,05$

** Различие является статистически значимым на уровне значимости $p<0,01$.

*** Различие является статистически значимым на уровне значимости $p<0,001$.

M1 - мотив эмоционального восприятия процесса действования; М3 - мотив самоутверждения; М9 - мотив принципиальной ответственности и добросовестности. 
Таблица 3

Статистическая значимость изменений в выраженности характеристик статусов в экспериментальной и контрольной группах по результатам двух измерений

\begin{tabular}{|c|c|c|c|c|c|c|}
\hline \multirow{3}{*}{$\begin{array}{l}\text { хар-ки } \\
\text { статуса }\end{array}$} & \multicolumn{3}{|c|}{ Экспериментальная выборка } & \multicolumn{3}{|c|}{ Контрольная выборка } \\
\hline & До программы & $\begin{array}{c}\text { После програм- } \\
\text { мы }\end{array}$ & \multirow[t]{2}{*}{$\begin{array}{c}\text { Критерий Вилкоксона } \\
\text { (p) }\end{array}$} & 1-е изм-е & 2-е изм-е & \multirow[t]{2}{*}{$\begin{array}{c}\text { Критерий Вилкоксона } \\
\text { (p) }\end{array}$} \\
\hline & \multicolumn{2}{|c|}{ Ср. арифметическое } & & \multicolumn{2}{|c|}{ Ср. арифметическое } & \\
\hline Диффузный & 0,36 & 0,20 & 0,21 & 0,40 & 0,48 & 0,53 \\
\hline Педопределенный & 0,64 & 0,20 & $0,0033^{* *}$ & 0,40 & 0,24 & 0,068 \\
\hline Мораторий & 4,36 & 3,72 & $0,0086^{* *}$ & 4,60 & 4,36 & 0,15 \\
\hline Достигнутый & 0,64 & 1,96 & $0,000089 * * *$ & 0,60 & 0,92 & 0,22 \\
\hline
\end{tabular}

** Различие является статистически значимым на уровне значимости $\mathrm{p}<0,01$.

*** Различие является статистически значимым на уровне значимости $\mathrm{p}<0,001$.

Изменение показателей статуса гражданской идентичности старших подростков до и после реализачии программы, в концептуальные основания которой заложена работа с исследуемыми психологическими детерминантами.

Приобретение достигнутого статуса гражданской идентичности представляет собой достаточно длительный период переосмысления и нельзя ожидать по результатам опытно-экспериментальной работы преобладания достигнутого статуса у подростков в экспериментальной выборке. Эффект работы может быть отсрочен. При оценке эффективности работы акцент сделан на анализе динамики профилей гражданской идентичности, то есть на количественные изменения в баллах, отражающие выраженность характеристик того или иного статуса.

С целью определения значимости сдвига в количественной выраженности характеристик статуса гражданской идентичности в личностных профилях подростков экспериментальной и контрольной выборок по результатам двух измерений применялся критерий Вилкоксона (таблица 3).

По итогам реализации программы выраженность характеристик предопределенного статуса и состояния моратория снизилась, а достигнутого - увеличилась. Отсутствие значимых изменений в выраженности характеристик диффузного статуса объясняется тем, что для выборки подростков, которые находятся в статусе мораторий изначально характерны очень низкие показатели выраженности диффузного статуса (средний балл 0,36).

В контрольной выборке по истечению времени равного периоду реализации программы изменений в выраженности характеристик статусов в личностных профилях обнаружено не было.

\section{Выво $\Delta ы$}

По итогам реализации программы установлены: прогрессивное изменение в способности к концептуализации в области гражданской проблематики; изменения в личностных профилях старшеклассников (увеличение выраженности положительной и уменьшение гиперпозитивной, негативной валентностей); увеличение рефлексивности; тенденция к ослаблению корреляционных связей между мотивом самоутверждения и мотивом ответственности и добросовестности; в социально значимой деятельности подростов возросли показатели мотива ответственности и добросовестности, мотива ориентации на пользу незнакомым людям.

Таким образом, психолого-педагогическая работа с выделенными в структуре гражданской идентичности детерминантами на когнитивном, эмоциональнооценочном и потребностно-мотивационном уровнях способствует формированию осознанной гражданской идентичности. Установлены изменения в статусных профилях гражданской идентичности старших подростков: уменьшение выраженности характеристик предопределенного статуса, состояния моратория и увеличение достигнутого статуса.

\section{ЛИТЕРАТУРА}

1. Асмолов А.Г. Формирование гражданской идентичности как ключевая задача образования и социокультурной модернизации России / А.Г. Асмолов, 0.А. Карабанова, М.С. Гусельцева [и др.]. - М.: Федеральный институт развития образования, 2012. 252 с.

2. Безгина Н.В. Психологическая структура гражданской идентичности // Известия ТулГУ. Гуманитарные науки. 2013. № 3-1. С. 241 -249. 
3. Буткин А.Г. Усвоение научных понятий в школе / А.Г, Буткин, И.А. Володарская, Н.Ф. Талызина. М.: Полиграф сервис, 1999. 112 с.

4. Дробовцева М.В., Котова М.В. Взаимосвязь гражданской и этнической идентичности россиян: факторы социокультурного контекста // Психологические исследования. 2016. T. 9, № 47. URL: http://psystudy.ru.

5. Евгеньева Т. В., Регнацкий В. В. Формирование национально-государственной идентичности московских школьников // Ценности и смыслы. 2015. № 2 (36). URL: https://cyberleninka.ru/article/n/formirovanie-natsionalno-gosudarstvennoy-identichnosti moskovskih-shkolnikov.

6. Ефремова 0.И. Психологические аспекты проявления чувства патриотизма у современной студенческой молодежи // Концепт. 2015. Спецвыпуск № 04. - URL: http://ekoncept.ru/2015/75074.htm.

7. Злоказов К.В., Леонов Н.И. Соотношение гражданского и религиозного аспектов социальной идентичности // Российский психологический журнал. 2016. № 3. C. 197-220.

8. Иванова Н.Л., Мазилова. Г.Б. Гражданская идентичность и формирование гражданственности // Известия Саратовского университета. Новая серия. Акмеология образования. Психология развития. 2010. № 4. С. 11-20.

9. Холодная М.А. Психология понятийного мышления: от концептуальных структур к понятийным способностям. М.: Изд-во Институт психологии РАН, 2012. $288 \mathrm{c}$.

10. Chorniy Y., Galchenko A. The research about psychological determinants of the civil identity formation in adolescence / SHS Web of Conferences, Volume 70,08013 (2019) // Trends in the Development of Psycho-Pedagogical Education in the Conditions of Transitional Society (ICTDPP-2019). I.V. Abakumova and E. V. Vorobyova (Eds.) - Rostov-on-Don, Russia, November 22-23, 2019.

11. Finell E., Liebkind K. National symbols and distinctiveness: Rhetorical strategies in creating distinct national identities // British Journal of Social Psychology. 2010. V. 49. I. 2. Pp. 321-341.

12. Kemmelmeier M., Winter D.G. Sowing patriotism, but reaping nationalism? Consequences of exposure to the American flag // Political Psychology. 2008. V. 29. I. 6. Pp. 859-879.

13. Meeus J., Duriez B., Vanbeselaere N., Boen F. The role of national identity representation in the relation between in-group identification and out-group derogation: Ethnic versus civic representation // British journal of social psychology. 2010. V. 49. Issue: 2. Pp. 305-320.

14. Scriven M., Paul R.W. Defining Critical Thinking // 8th Annual International Conference on Critical Thinking and Education Reform, Summer 1987. - National Council for Excellence in Critical Thinking.

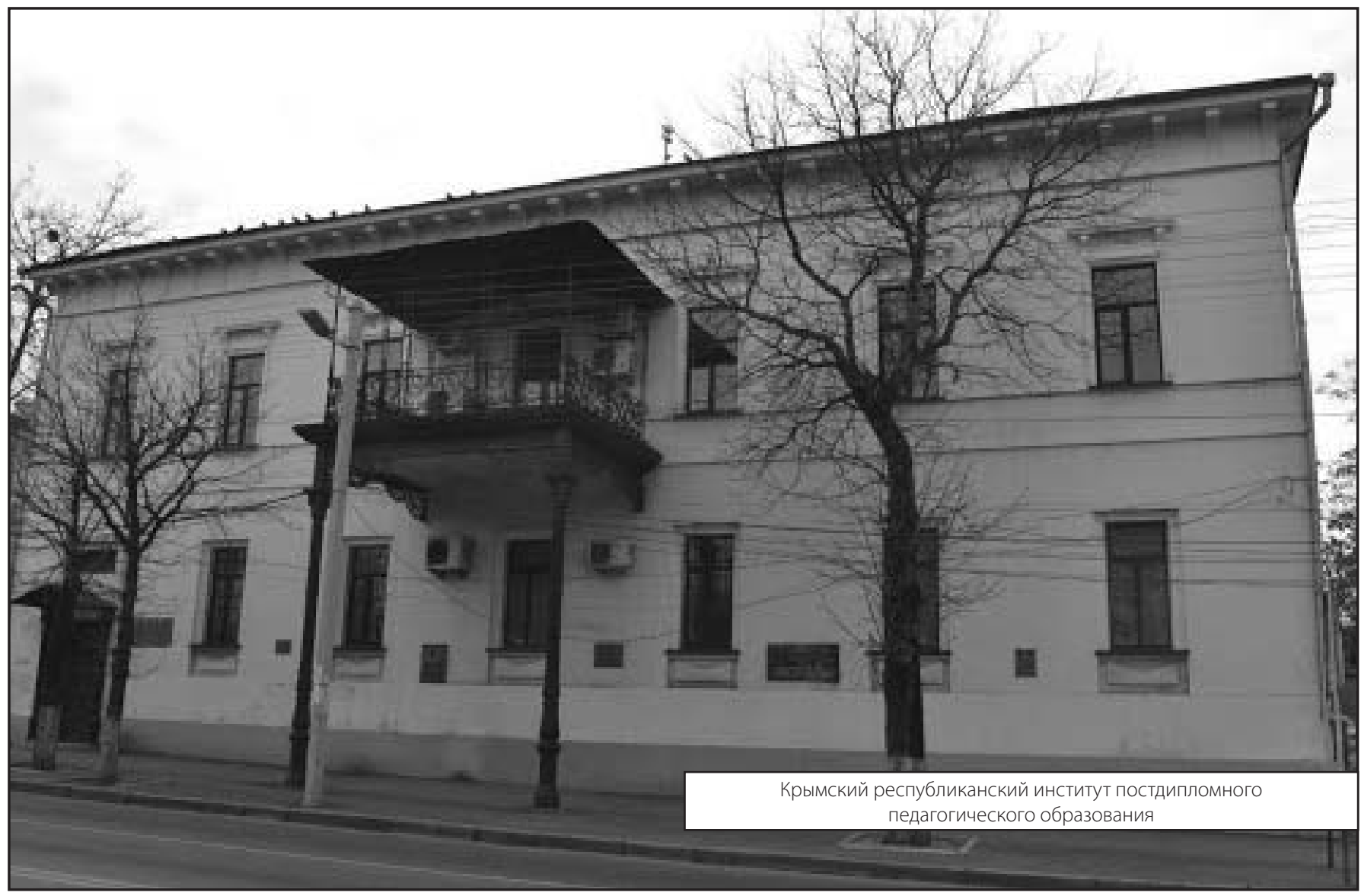

